\title{
2892. Analysis on monitoring and controlling techniques about blasting vibration effect of open channel in Taishan nuclear power station
}

\author{
Yongqing Zeng ${ }^{1}$, Haibo $\mathrm{Li}^{2}$, Xiang $\mathrm{Xia}^{3}$, Yaqun $\mathrm{Liu}^{4}$, Hong Zuo ${ }^{5}$, Jinlin Jiang ${ }^{6}$ \\ $1,5,6$ University of Chinese Academy of Sciences, Beijing, 100049, China

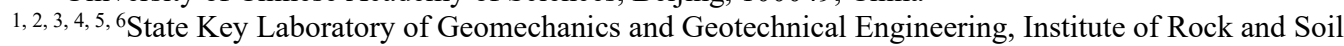 \\ Mechanics, Chinese Academy of Sciences, Wuhan, 430071, China \\ ${ }^{1}$ Corresponding author \\ E-mail: ${ }^{1} y q z e n g @ w h r s m . a c . c n,{ }^{2} h b l i @ w h r s m . a c . c n,{ }^{3} x x i a @ w h r s m . a c . c n,{ }^{4} y q l i u @ w h r s m . a c . c n$, \\ 5hzuo@whrsm.ac.cn, ${ }^{6} j \mathrm{j} @ w h u . e d u . c n$
}

Received 1 November 2017; received in revised form 6 March 2018; accepted 15 March 2018 DOI https://doi.org/10.21595/jve.2018.19341

Check for updates

Copyright (C) 2018 Yongqing Zeng, et al. This is an open access article distributed under the Creative Commons Attribution License, which permits unrestricted use, distribution, and reproduction in any medium, provided the original work is properly cited.

\begin{abstract}
The blasting for bedrock excavation on land for open channel project has a great influence on lock gate in Taishan Nuclear Power Station, therefore, based on blasting vibration monitoring data, the attenuation law of blasting vibration signal has been studied through regression analysis of practical test data by Sadaovsk empirical formula and corresponding time-frequency characteristics was analyzed by Empirical Mode Decomposition based on Hilbert-Huang transform. As for those monitoring data, the results of blast vibration velocity for vertical direction are generally larger than horizontal radial and horizontal tangential direction in the near field of blasting source and the peak particle velocity of vertical direction is usually lower than horizontal radial and horizontal tangential direction in the far field of blasting source; at the same time, their main vibration frequency mostly vary from $10 \mathrm{~Hz}$ to $80 \mathrm{~Hz}$ which is much higher than natural frequency of lock gate and is beneficial to structural safety and stability of surrounding rock mass for reducing the probability of resonance. To ensure the safety of lock gate, it is of great significance to control maximum explosive weight per delay in advance for different distance from monitoring point to the explosion source according to Safety Regulations for Blasting (GB6722-2014), which shows the excellent effect on blasting damage control of the lock gate and surrounding rock mass. The results from the analysis can be for reference to similar blasting design and blasting construction.
\end{abstract}

Keywords: blasting vibration effect, open channel, vibration monitoring, attenuation law, blasting control, Hilbert-Huang transform.

\section{Nomenclature}

$\begin{array}{ll}\sigma & \text { Stress of structure body } \\ E & \text { Elastic modulus } \\ \varepsilon & \text { Strain } \\ v & \text { Particle vibration velocity } \\ c & \text { Propagation speed of vibration wave } \\ Q & \text { Maximum explosive weight per delay } \\ R & \text { Distance between the monitoring point and blasting source } \\ K & \text { Blasting design and field geology coefficient } \\ \alpha & \text { Attenuation coefficient } \\ \rho & \text { Proportional charge weight } \\ X(t) & \text { Raw signal } \\ c_{i}(t) & \text { Intrinsic mode function } \\ r_{n}(t) & \text { Residual error } \\ H[c(t)] & \text { Hilbert-Huang transform for intrinsic mode function }\end{array}$




$\begin{array}{ll}z(t) & \text { Analytic signal } \\ a(t) & \text { Amplitude value function } \\ \Phi(t) & \text { Phase function } \\ \omega(t) & \text { Transient frequency } \\ H(\omega, t) & \text { Hilbert spectrum amplitude } \\ E S(w) & \text { Hilbert energy spectrum }\end{array}$

\section{Introduction}

With the rapid development of national economy and the sustainable progress of science technology, the blasting technology is increasingly applied to engineering field such as highway excavation, channel blasting compaction, mining, building demolition, seismic exploration and explosive fabrication $[1,2]$. Blasting stress wave is unavoidable in engineering blasting, which brought a series of serious problems such as ground vibration, blasting slungshot, building crack, landslide, tunnel collapse and many other hazards; therefore, the research on safety control on blasting vibration effect has the vital significance $[3,4]$.

At present, the research on effect of blasting vibration mainly concentrate on architectural structure, highway on ground, coal mining and shallow tunnel, Wei [5] theoretically analyzed the time-distance effect of blasting seismic waves from a point explosion source based on several examples of blasting near to buildings in Guangzhou and the vibration responses of structure and non-structure of buildings were calculated by the time-distance effect analysis method. Wang [6] monitored the surface building vibration to control and evaluate the impact of the underground blasting vibration on the surface building during the excavation of a big span tunnel in underground of the downtown areas with intensive buildings at Huangnipang shallow light rail station in Chongqing city. Jiang [7] analysed vibration data and adopted several vibration damping technologies to actualize large blasting excavation in a city with background of a garden building foundation and an underground garage excavation blasting. Lin [8] studied the stability control technology of tunnel and the field monitoring technique which is used to obtain the blasting vibration velocity and regression analysis result according to the modern information construction theory in the Damaoshan tunnel when blasting construction on new-built tunnel. Zeng [9] studied effect of blasting vibration on stability of surface buildings in order to mine the shallow remnant antimony ore in Wulongdao mining area and to ensure the security of the surface architecture during underground mining blasting. Wang [10] researched blasting vibration effect of coalmine soft rock roadway excavation and its impact on roadway loose circle radius based on testing and analysis of blasting vibration and excavation damage zone. Zong [11] studied the frequency spectrum characteristics and energy distribution of blasting seismic wave signal in coalmine roadway excavation by using the HHT method and EMD decomposition. Huo [12] studied failure mechanism of the dams and tunnel structures in different blasting method and put forward a blasting safety rule for the hydraulic structures. Xu [13] and Jiang et al. [14] discusses blasting vibration monitoring and blasting control technologies in construction of cross tunnels with super small interval in the space and parallel tunnels with small interval on the plane based upon field monitoring data.

However, it has seldom referred to vibration effect of the blasting for rock excavation in nuclear power station. Along with the fast social and economic development, energy problem is becoming much more urgent. Nuclear power has a giant using value as a clean and economic energy. In the process of nuclear power station construction, blasting method still has an important role as an available and relatively economic method, it inevitably involve blasting vibration monitoring and initiative control of blasting damage $[15,16]$. The study on how to determine vibration characteristics of blasting vibration signal has importantly and imminently practical significance. The blasting for bedrock excavation on land for open channel project is conducted in Taishan Nuclear Power Station, which has a great influence on lock gate and surrounding rock mass, therefore, based on blasting vibration monitoring data, the attenuation law of blasting 
vibration signal has been studied through regression analysis of practical test data by Sadaovsk empirical formula and corresponding time-frequency characteristics was analyzed by Empirical Mode Decomposition based on Hilbert-Huang transform. At the same time, according to Safety Regulations for Blasting (GB6722-2014), the technical measures such as controlling the maximum explosive weight per delay and millisecond delay blasting is put forward for reducing the blasting effect, which shows the excellent effect on blasting damage control of the lock gate and surrounding rock mass.

\section{Theory}

\subsection{Characteristics of wave propagation}

Assuming structural body vibrate for the effect of disturbance, according to elasticity theory and wave theory, we can find that:

$\begin{aligned} \sigma & =E \varepsilon \\ \varepsilon & =\frac{v}{c}\end{aligned}$

where $\sigma$ is the stress of structure body for blasting, $E$ is elastic modulus, $\varepsilon$ is strain and $v, c$ is particle vibration velocity, propagation speed of vibration wave, respectively.

Substitution of Eq. (2) into Eq. (1) gives:

$\sigma=E \frac{v}{c}$

It can be seen from Eq. (3) that the stress of the structure for blasting is proportional to vibration velocity of the particle and that the particle vibration velocity is an important physical quantity of structural damage where the speed of vibration can reflect the blast-induced damage and the test is convenient and reliable.

In general, ground vibration velocity is approximately related to the distance between the monitoring point and blasting source, $R$, and the maximum explosive weight per delay, $Q$. According to Safety Regulations for Blasting [17], the Sadaovsk empirical formula points out:

$v=K(\rho)^{\alpha}=K\left(\frac{Q^{1 / 3}}{R}\right)^{\alpha}$,

where $Q$ is the maximum explosive weight per delay, $R$ is the distance between the monitoring point and blasting source, $\rho=\sqrt[3]{Q} / R$ is proportional charge weight, $K$ is the blasting design and field geology coefficient, and $a$ is the attenuation coefficient.

\subsection{Hilbert-Huang transform}

Hilbert-Huang transform is composed of Empirical Mode Decomposition (EMD) and Hilbert Spectrum Analysis (HSA). N. E. Huang believes that arbitrarily complicated signal can be composed of a series of Intrinsic Mode Function (IMF) which is simple, inharmonic and separate from each other. Hilbert-Huang transform was put forward based on above views and Empirical Mode Decomposition is the most important procedure of Hilbert-Huang transform [18].

Using Empirical Mode Decomposition, a raw signal $X(t)$ can be expressed as follows [19]: 
$X(t)=\sum_{i=1}^{n} c_{i}(t)+r_{n}(t)$,

where $X(t)$ is a raw signal; $c_{i}(t)$ is intrinsic mode function and $r_{n}(t)$ is residual error.

Using Hilbert-Huang transform for every intrinsic mode function $c(t)$ :

$H[c(t)]=\frac{1}{\pi} P V \int_{-\infty}^{\infty} \frac{c\left(t^{\prime}\right)}{t-t^{\prime}} d t^{\prime}$,

where $P V$ is Cauchy principal value, we can obtain analytic signal $z(t)$ :

$z(t)=c(t)+j H[c(t)]=a(t) e^{j \Phi(t)}$,

where $a(t)$ is amplitude value function:

$a(t)=\sqrt{c^{2}(t)+H^{2}[c(t)]}$,

and $\Phi(t)$ is phase function:

$\Phi(t)=\arctan \frac{H[c(t)]}{c(t)}$.

Transient frequency is determined by derivation for phase function $\Phi(t)$ :

$\omega(t)=\frac{d \Phi(t)}{d t}$.

The amplitude and frequency derived from Hilbert-Huang transform is a function about time, by expressing the change of amplitude as frequency and time change, we can obtain Hilbert spectrum:

$H(\omega, t)=R e \sum_{i=1}^{n} a_{i}(t) e^{\int \omega_{j}(t) d t}$.

Hilbert energy spectrum $E S(w)$ is obtained from the time integration of the square of Hilbert spectrum amplitude $H(\omega, t)$ :

$E S(w)=\int_{0}^{T} H^{2}(w, t) d t$

Hilbert energy spectrum $E S(w)$ provides an expression of energy calculation for every frequency and is defined as total energy accumulation in long-term span for every frequency.

In contrast with traditional Fourier transform using a series of harmonic wave to simulate vibration signal and Wavelet transform with the problem on selection of wavelet basis function, Hilbert-Huang transform has no constant and preset basis function and has better identifying ability in local region of blasting vibration signal.

\subsection{Safety criterion of blasting vibration effect}

Due to the complexity of blasting seismic wave propagation and the diversity of influencing factors, there are great differences in engineering standards for safety criterion of blasting seismic 
effect adopted at home and abroad [20,21]. For rock and concrete materials, the dynamic tensile strength plays a major role in the safety and stability of the material itself and its structure under the blasting load. The dynamic tensile stress is proportional to the particle vibration velocity, thus the early safety criterion of blasting vibration effect is based on single peak vibration velocity to judge whether the structure and the building is safe or not, such as Longerfors [22], Edwards [23], Fogelson [24], Northwood [25] and Bollinger [26], etc. all taking single particle vibration velocity (or acceleration) as safety criterion.

With the development of the theory and technology for blasting engineering, the researchers found that the frequency and velocity both has great influence on the engineering facilities, using a single strength parameter as the basis of safety standards evaluation for blasting vibration has great limitation. In this way, for many countries, such as Germany, the United States, Switzerland and China, the vibration velocity and frequency are taken into account when the safety standards for blasting vibration are formulated.

According to the United States Bureau of Mines (USBM) and Office of Surface Mining Reclamation and Enforcement (OSMRE) in American [20], the safety criterion of USBM and OSMRE is shown in Fig. 1.

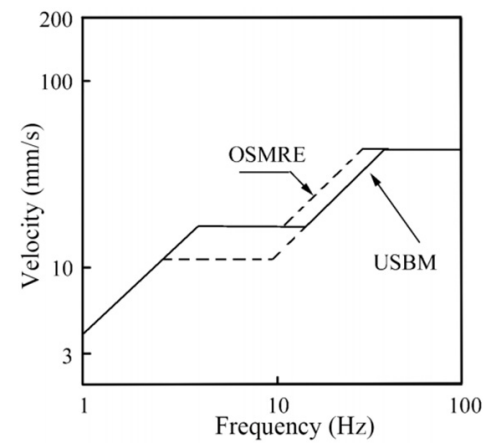

Fig. 1. Safety criteria of USBM and OSMRE

Table 1. Safe allowable standards for blasting vibration

\begin{tabular}{|c|c|c|c|c|}
\hline \multirow{2}{*}{$\begin{array}{c}\text { Sequence } \\
\text { number }\end{array}$} & \multirow{2}{*}{ Object of protection } & \multicolumn{3}{|c|}{ Allowable limit of particle vibration velocity $(\mathrm{cm} / \mathrm{s})$} \\
\hline & & $f \leq 10 \mathrm{~Hz}$ & $10 \mathrm{~Hz}<f \leq 50 \mathrm{~Hz}$ & $f>50 \mathrm{~Hz}$ \\
\hline 1 & $\begin{array}{l}\text { Cave dwelling, adobe building } \\
\text { and rubble building }\end{array}$ & $0.15-0.45$ & $0.45-0.9$ & $0.9-1.5$ \\
\hline 2 & Common civil building & $1.5-2.0$ & $2.0-2.5$ & $2.5-3.0$ \\
\hline 3 & $\begin{array}{l}\text { Industrial building } \\
\text { and commercial building }\end{array}$ & $2.5-3.5$ & $3.5-4.5$ & $4.2-5.0$ \\
\hline 4 & $\begin{array}{l}\text { General ancient architecture } \\
\text { and historic site }\end{array}$ & $0.1-0.2$ & $0.2-0.3$ & $0.3-0.5$ \\
\hline 5 & $\begin{array}{l}\text { Central control room equipment at } \\
\text { hydropower station } \\
\text { and power plant in service }\end{array}$ & $0.5-0.6$ & $0.6-0.7$ & $0.7-0.9$ \\
\hline 6 & Hydraulic tunnel & $7-8$ & $8-10$ & $10-15$ \\
\hline 7 & Traffic tunnel & $10-12$ & $12-15$ & $15-20$ \\
\hline 8 & Mine tunnel & $15-18$ & $18-25$ & $20-30$ \\
\hline 9 & Permanently high rock slope & $5-9$ & $8-12$ & $10-15$ \\
\hline 10 & $\begin{array}{c}\text { The new pouring mass concrete }(\mathrm{C} 20) \text { : } \\
\text { Curing time: initial solidification - 3d } \\
\text { Curing time: } 3 \mathrm{~d}-7 \mathrm{~d} \\
\text { Curing time: } 7 \mathrm{~d}-28 \mathrm{~d}\end{array}$ & $\begin{array}{l}1.5-2.0 \\
3.0-4.0 \\
7.0-8.0\end{array}$ & $\begin{array}{l}2.0-2.5 \\
4.0-5.0 \\
8.0-10.0\end{array}$ & $\begin{array}{l}2.5-3.0 \\
5.0-7.0 \\
10.0-12\end{array}$ \\
\hline
\end{tabular}

The "Safety regulations for blasting" (GB6722-2014) in China specified safety criterion of blasting vibration for the ground building, central control room equipment at hydropower station 
and power plant in service, hydraulic tunnel, traffic tunnel, mine tunnel, high rock slope and the new pouring mass concrete, etc. based on peak particle velocity and the main vibration frequency. Safe allowable standards for blasting vibration are listed in Table 1, for different protection object, the allowable limit of particle vibration velocity is different at diverse range of main vibration frequency. When the main vibration frequency is $f \leq 10 \mathrm{~Hz}, 10 \mathrm{~Hz}<f \leq 50 \mathrm{~Hz}$ and $f>50 \mathrm{~Hz}$, respectively, for the common civil building, the allowable limit of particle vibration velocity is $1.5-2.0 \mathrm{~cm} / \mathrm{s}, 2.0-2.5 \mathrm{~cm} / \mathrm{s}$ and $2.5-3.0 \mathrm{~cm} / \mathrm{s}$, respectively; for the hydraulic tunnel, the safety criteria of particle vibration velocity is $7-8 \mathrm{~cm} / \mathrm{s}, 8-10 \mathrm{~cm} / \mathrm{s}$ and $10-15 \mathrm{~cm} / \mathrm{s}$, respectively. Besides, different control standards are adopted for new pouring mass concrete (C20) of varying ages, when the main vibration frequency is $f \leq 10 \mathrm{~Hz}, 10 \mathrm{~Hz}<f \leq 50 \mathrm{~Hz}$ and $f>50 \mathrm{~Hz}$, respectively, for curing time between initial solidification and $3 \mathrm{~d}$, the allowable limit of particle vibration velocity is $1.5-2.0 \mathrm{~cm} / \mathrm{s}, 2.0-2.5 \mathrm{~cm} / \mathrm{s}$ and $2.5-3.0 \mathrm{~cm} / \mathrm{s}$, respectively; for curing time between $3 \mathrm{~d}$ and $7 \mathrm{~d}$, the allowable limit of particle vibration velocity is $3.0-4.0 \mathrm{~cm} / \mathrm{s}, 4.0-5.0 \mathrm{~cm} / \mathrm{s}$ and $5.0-7.0 \mathrm{~cm} / \mathrm{s}$, respectively; for curing time between $7 \mathrm{~d}$ and $28 \mathrm{~d}$, the allowable limit of particle vibration velocity is $7.0-8.0 \mathrm{~cm} / \mathrm{s}, 8.0-10.0 \mathrm{~cm} / \mathrm{s}$ and $10.0-12 \mathrm{~cm} / \mathrm{s}$, respectively.

\section{Case study}

\subsection{Introduction to Taishan nuclear power station}

The project, Taishan Nuclear Power Station, is located in Taishan city, the south of Guangdong Province, China. Its geographical location is at longitude $112^{\circ} 59^{\prime} \mathrm{E}$ and latitude $21^{\circ} 54^{\prime} \mathrm{N}$, which is located to the east of the Huangmao Sea and is about $5 \mathrm{~km}$ from the southeast of Dajin Island. The project construction scale is preliminarily to $6 \times 1750 \mathrm{MW}$ European pressurized water reactor (EPR) which will be divided into three phases and two EPR nuclear power units are planned in the first phase. According to the design requirements, the construction of the $0+000$ to $0+200 \mathrm{~m}$ mileage section of the open channel for phase I of Taishan nuclear power station project requires the ground blasting and underwater reef blasting for rock excavation. The excavation of the rock is about $257361.35 \mathrm{~m}^{3}$, of which about $53954.25 \mathrm{~m}^{3}$ is excavated in land and about $203407.1 \mathrm{~m}^{3}$ is excavated in the submerged reef. The blasting site for rock excavation of open channel on land in Taishan is shown in Fig. 2.

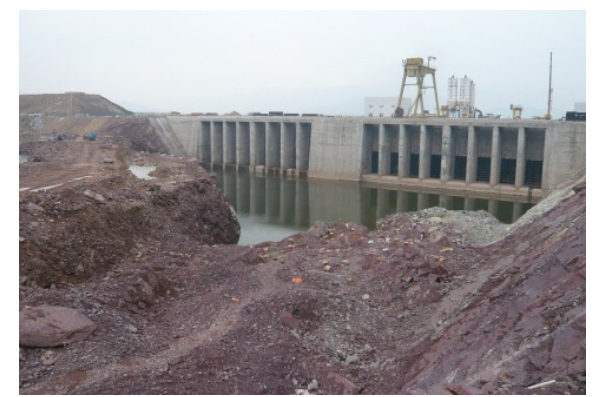

Fig. 2. The blasting site for rock excavation of open channel on land in Taishan

Because blasting stress wave in bedrock blasting excavation may give rise to damage for No. 1-No. 2 lock gate of water tunnel, it is necessary to carry out blast-induced damage control. The main purpose of monitoring is to validate the feasibility and the rationality of the blasting design parameters for blasting scheme and to correctly guide the construction using the attenuation law and time-frequency characteristics of monitoring results.

\subsection{Monitoring and attenuation law for blasting vibration signal}

Due to the TC-4850 blasting vibration monitoring system has the advantages of small size, 
light weight, high sensitivity and high automation, it is extraordinary suitable for the need of large quantities and long duration for rock blasting vibration monitoring. The field blasting vibration monitoring points are arranged in the near side of the open channel above the explosion zone, in which the attenuation law of blasting vibration signal for the lock gate is monitored by three vector sensors which can monitor horizontal radial, horizontal tangent and vertical direction at each measuring point during the blasting excavation. The blasting vibration monitoring system for bedrock excavation blasting and the layout of blasting vibration monitoring point of three vector sensor are shown in Fig. 3.

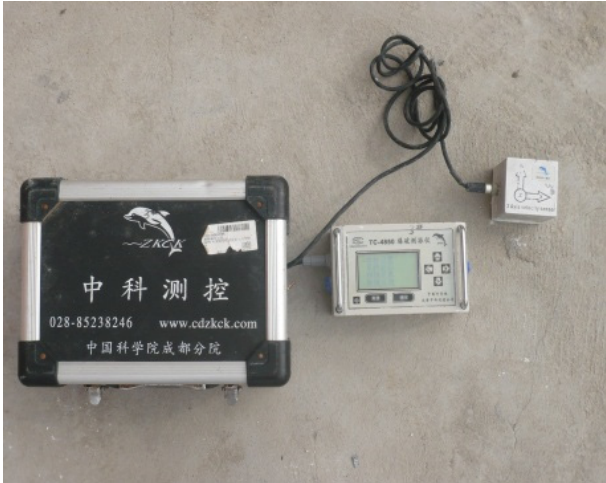

a) The blasting vibration monitoring system

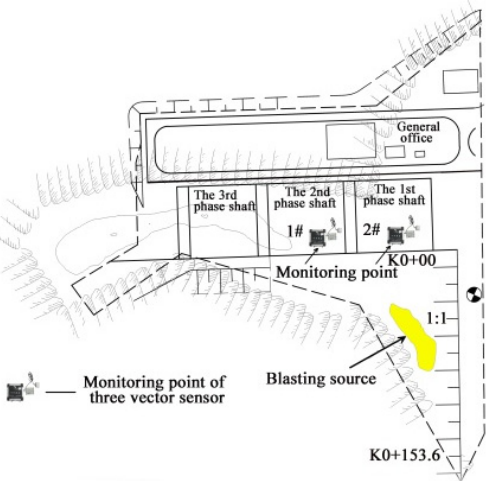

b) The layout of blasting vibration monitoring points Fig. 3. The blasting vibration monitoring system and layout of blasting vibration monitoring points

Table 2. Parts of monitoring results of peak particle velocity under explosion

\begin{tabular}{|c|c|c|c|c|c|c|c|c|}
\hline \multirow{2}{*}{$\begin{array}{c}\text { Maximum } \\
\text { explosive weight } \\
\text { per delay }(\mathrm{kg})\end{array}$} & \multirow{2}{*}{$\begin{array}{c}\text { Total } \\
\text { explosive } \\
\text { weight }(\mathrm{kg})\end{array}$} & \multirow{2}{*}{$\begin{array}{l}\text { Distance } \\
\text { (m) }\end{array}$} & \multicolumn{2}{|c|}{$\begin{array}{c}\text { Horizontal } \\
\text { radial direction }\end{array}$} & \multicolumn{2}{|c|}{$\begin{array}{c}\text { Horizontal } \\
\text { tangential } \\
\text { direction }\end{array}$} & \multicolumn{2}{|c|}{$\begin{array}{l}\text { Vertical } \\
\text { direction }\end{array}$} \\
\hline & & & $\begin{array}{c}v \\
(\mathrm{~cm} / \mathrm{s})\end{array}$ & $\begin{array}{c}f \\
(\mathrm{~Hz})\end{array}$ & $\begin{array}{c}v \\
(\mathrm{~cm} / \mathrm{s})\end{array}$ & $\begin{array}{c}f \\
(\mathrm{~Hz})\end{array}$ & $\begin{array}{c}v \\
(\mathrm{~cm} / \mathrm{s})\end{array}$ & $\begin{array}{c}f \\
(\mathrm{~Hz})\end{array}$ \\
\hline 96 & 240 & 225 & 1.11 & 15.6 & 0.17 & 25.0 & 0.82 & 17.5 \\
\hline 108 & 336 & 122 & 0.78 & 21.5 & 0.73 & 29.8 & 1.01 & 22.9 \\
\hline 108 & 408 & 106 & 0.91 & 25.6 & 0.92 & 41.7 & 0.67 & 19.6 \\
\hline 110 & 984 & 54 & 3.00 & 10.7 & 2.01 & 40.0 & 4.70 & 19.0 \\
\hline 144 & 768 & 184 & 0.73 & 17.2 & 0.38 & 18.9 & 0.70 & 15.9 \\
\hline 150 & 960 & 210 & 0.80 & 13.9 & 0.28 & 14.7 & 0.79 & 58.8 \\
\hline 150 & 1168 & 143 & 1.46 & 16.1 & 0.47 & 11.7 & 1.55 & 22.5 \\
\hline 160 & 1392 & 47 & 3.98 & 16.3 & 3.11 & 33.2 & 9.43 & 47.4 \\
\hline 180 & 768 & 191 & 0.52 & 12.5 & 0.51 & 10.8 & 0.18 & 12.5 \\
\hline 190 & 816 & 145 & 1.43 & 16.1 & 0.54 & 45.9 & 2.11 & 46.4 \\
\hline 188.5 & 1248 & 58 & 5.55 & 20.5 & 1.95 & 10.7 & 5.79 & 32.2 \\
\hline 200 & 1176 & 51 & 4.16 & 7.30 & 3.09 & 11.2 & 9.64 & 69.8 \\
\hline 200 & 1680 & 60 & 5.55 & 20.5 & 1.95 & 10.7 & 5.79 & 32.2 \\
\hline 240 & 1576 & 64 & 2.72 & 21.6 & 2.73 & 24.6 & 2.84 & 29.7 \\
\hline 240 & 1152 & 347 & 0.22 & 9.30 & 0.30 & 14.6 & 0.62 & 20.1 \\
\hline 300 & 1968 & 96 & 1.81 & 10.7 & 1.65 & 25.9 & 3.54 & 34.2 \\
\hline 300 & 2904 & 362 & 0.51 & 15.6 & 0.18 & 15.6 & 0.74 & 46.9 \\
\hline 340 & 1080 & 91 & 2.03 & 11.2 & 1.89 & 10.7 & 4.19 & 17.1 \\
\hline 350 & 1248 & 147 & 1.25 & 17.1 & 0.87 & 11.7 & 2.06 & 16.6 \\
\hline 450 & 1080 & 114 & 4.14 & 32.3 & 1.09 & 40.0 & 3.84 & 21.7 \\
\hline 800 & 1608 & 114 & 3.84 & 26.3 & 1.56 & 27.0 & 2.83 & 23.8 \\
\hline
\end{tabular}

Altogether 168 blasting vibration data along the horizontal radial, horizontal tangential and vertical direction were recorded from 56 blasts. Parts of monitoring results of peak particle 
velocity under explosion are shown in Table 2.

Total 123 blasting vibration data from 41 blasts from controlled blasting and bench blasting are selected to fit in the form of power function based on Eq. (4) for bedrock excavation blasting. The regression analysis results of peak particle velocity along the horizontal radial, horizontal tangential and vertical direction are shown in Fig. 4.

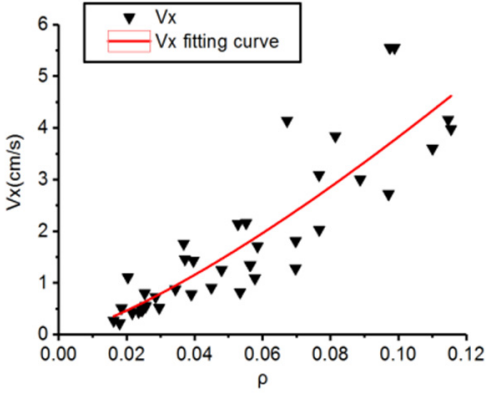

a) Horizontal radial direction

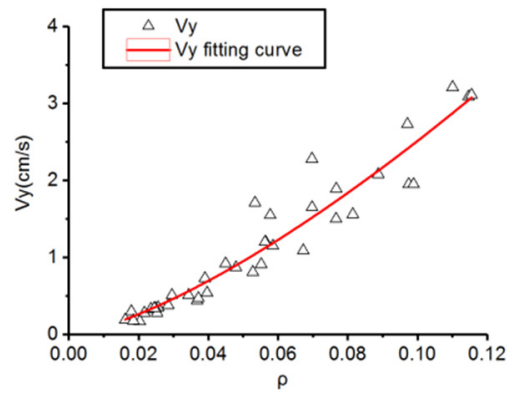

b) Horizontal tangential direction

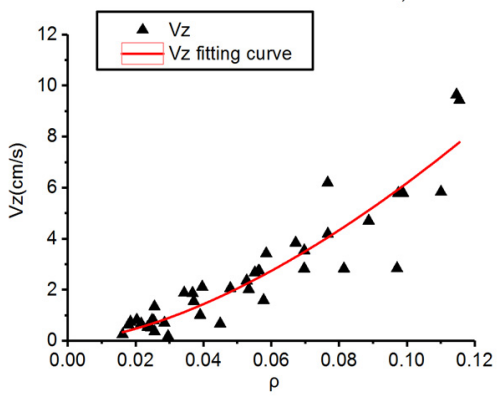

c) Vertical direction

Fig. 4. The regression analysis of blast vibration velocity, $v$, and the proportional charge weight, $\rho$

The Sadaovsk empirical formula on regressive analysis along the horizontal radial, horizontal tangential and vertical direction is expressed as Eqs. (13-15), respectively:

$v_{x}=77.3\left(\frac{Q^{1 / 3}}{R}\right)^{1.31}$,

$v_{y}=63.2\left(\frac{Q^{1 / 3}}{R}\right)^{1.40}$

$v_{z}=241.8\left(\frac{Q^{1 / 3}}{R}\right)^{1.56}$.

The blast-induced wave propagation law is obtained in the form of Eqs. (13-15), based on the above equation, we can effectively present the blasting design about the maximum explosive weight per delay, $Q$, according to the allowable peak particle velocity, $v_{\max }$, at different distance from the explosion source, $R$, in terms of requisition of "Safety regulations for blasting" (GB6722-2014) in China, which shows the excellent control effect on blasting damage of the lock gate and surrounding rock mass.

It is observed in Eqs. (13-15) that the range of variation for $K$ is from 63.2 to 241.8 and $\alpha$ is from 1.31 to 1.56 that belongs to the range of medium and hard rock, which is consistent with the previous exploration of formation lithology, where it has been observed that $K, \alpha$ of vertical direction is largest, this is, 241.8 and 1.56 , respectively but $K, \alpha$ of horizontal radial direction is 77.3 and 1.31 , respectively and $K, \alpha$ of horizontal tangential is 63.2 and 1.40 , respectively. 
In term of Sadaovsk empirical formula in Eq. (4), parameter $K$ is directly proportional to particle vibration velocity and parameter $\alpha$ represent attenuation speed of particle vibration velocity where the bigger of $\alpha$, the faster of velocity attenuation along propagation distance. By comparing the difference of $K$ and $\alpha$ for horizontal radial, horizontal tangential and vertical direction, we easily find that the $K$ of vertical direction is more than horizontal radial and horizontal tangential direction while $\alpha$ of vertical direction is also more than horizontal radial and horizontal tangential direction which show that vertical direction has faster speed of velocity attenuation, it imply that even though peak particle velocity of vertical direction is generally larger than horizontal radial and horizontal tangential direction in the near field of blasting source, however, the peak particle velocity of vertical direction will be lower than horizontal radial and horizontal tangential direction in the far field of blasting source which is consistent with the results shown in Table 2. So, it is noteworthy that we should take three different direction components of particle vibration velocity rather than single direction into account as safety criteria for blasting vibration.

\subsection{Time-frequency characteristics for blasting vibration signal}

As seen in Fig. 5, there is a typical multiple section raw signal of blasting seismic wave. The sampling points are 2000 and sampling interval time is $0.0005 \mathrm{~s}$. The original vibration signal (Fig. 5) is decomposed and reconstructed by Empirical Mode Decomposition, the decomposed vibration signal is shown in Fig. 6 and the reconstructed vibration signal and relative error are shown in Fig. 7.

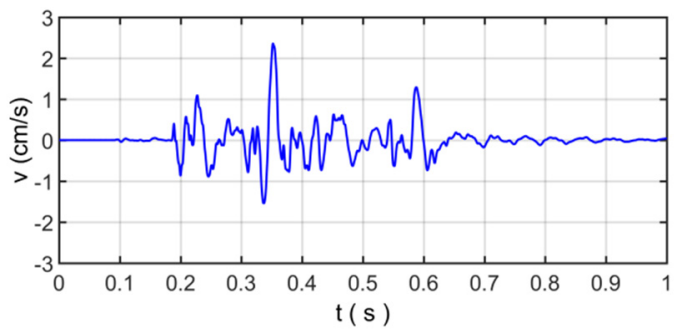

Fig. 5. The blasting site for rock excavation of open channel on land in Taishan

Fig. 6 shows that the original vibration signal is decomposed into 9 intrinsic mode functions from $\mathrm{c} 1$ to $\mathrm{c} 8$ and $R$ for residual error. Because Empirical Mode Decomposition always decompose raw vibration signal based on time scales from big to small, the waveform of intrinsic mode functions are becoming more and more longer while the frequency is becoming more and more lower with the proceed of decomposition. The intrinsic mode functions commonly have distinctly physical implication: The $\mathrm{cl}$ component has the highest frequency and the energy is very small, which indicates that it is usually considered to be a high frequency noise that needs to be denoised in the process of analysis on frequency spectrum characteristics for blasting vibration signal. The c2, c3, c4, c5 and c6 component have larger amplitude than other intrinsic mode functions and contain a majority of energy of original vibration signal which become main component to influence of building vibration; the c7 and c8 component have less frequency, amplitude and energy of original vibration signal coming from resident signal or other factors. Residual error $\mathrm{R}$ reflects the zero-drift phenomenon or weak change tendency of signal with the lowest amplitude and energy.

As is shown in Fig. 7, the reconstructed vibration signal based on Empirical Mode Decomposition is very consistently similar to original vibration signal with relative error is within in $10^{-15}$, which shows that Hilbert-Huang transform, and Empirical Mode Decomposition can accurately reflect the characteristics of the non-stationary signal and have an excellent suitability for analysis on blasting vibration signal. 
Fig. 8 shows power spectrum density of original vibration signal (Fig. 5) and Fig. 9 shows power spectrum density of intrinsic mode functions from $\mathrm{c} 1$ to $\mathrm{c} 8$ and $R$ (Fig. 6).
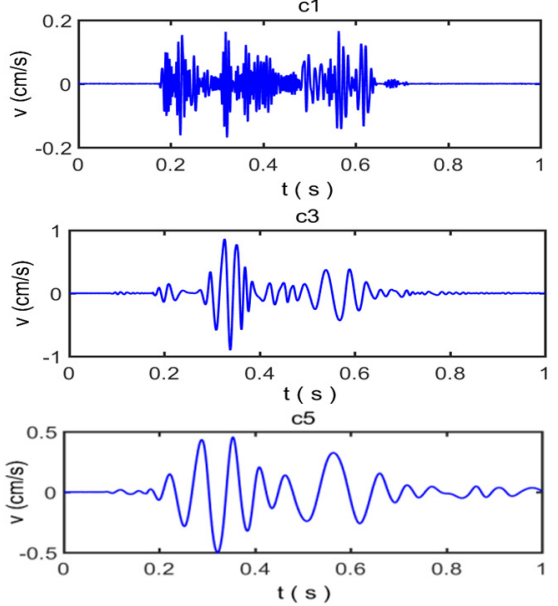

c7

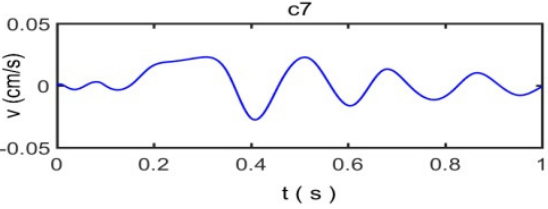

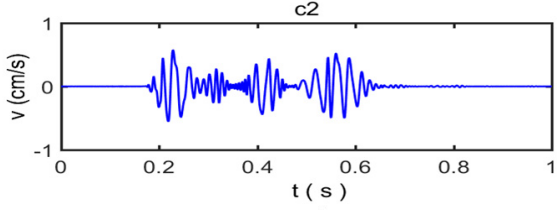
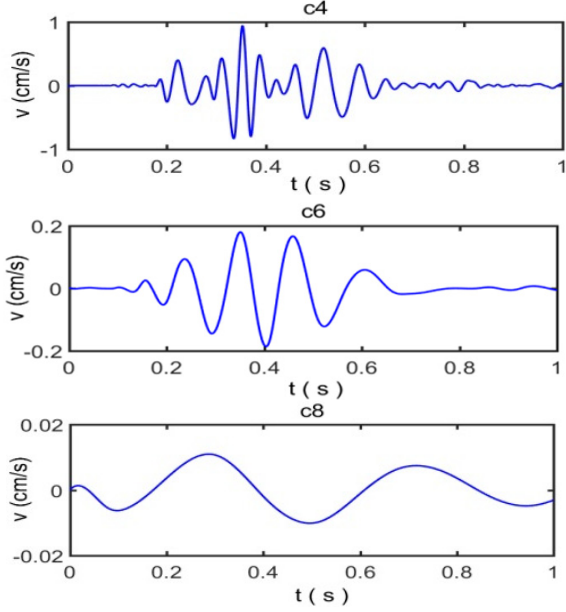

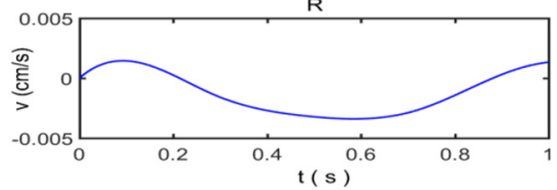

Fig. 6. The decomposed vibration signal by empirical mode decomposition

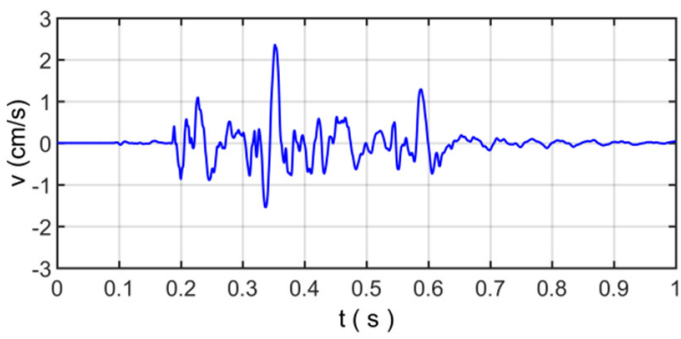

a) Reconstruction signal based on empirical mode decomposition

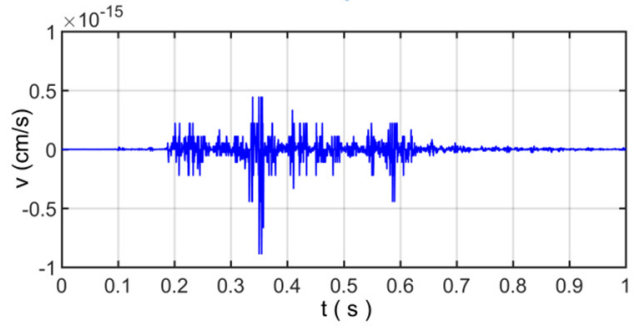

b) Relative error based on empirical mode decomposition

Fig. 7. The reconstruction of signal and relative error based on empirical mode decomposition

Fig. 8 indicates the blast energy of original vibration signal mainly concentrate on the region where frequency is below $80 \mathrm{~Hz}$ and has three sub-band which varies from $10 \mathrm{~Hz}$ to $18 \mathrm{~Hz}$, from $22 \mathrm{~Hz}$ to $45 \mathrm{~Hz}$ and from $50 \mathrm{~Hz}$ to $80 \mathrm{~Hz}$, respectively, in which the main energy concentrates in the range of $10 \mathrm{~Hz}$ to $45 \mathrm{~Hz}$, and the energy in the range of $50 \mathrm{~Hz}$ to $80 \mathrm{~Hz}$ is relatively weak and uniformly distributed. The natural frequencies of common lock gate are between $2 \mathrm{~Hz}$ and $5 \mathrm{~Hz}$, from the perspective of security, low energy distribution in the low frequency region is beneficial to structural safety and stability of surrounding rock mass for reducing the probability of resonance $[11,27]$. 


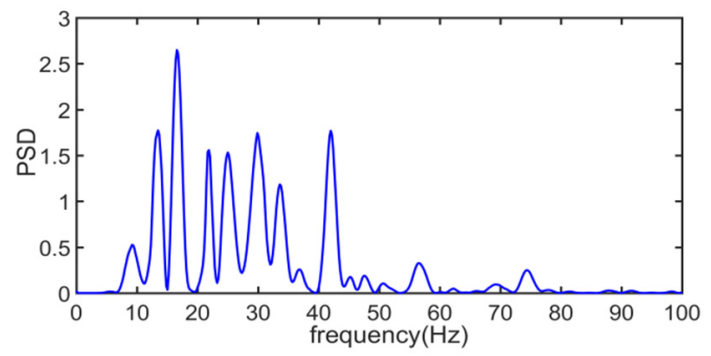

Fig. 8. The power spectral density of original blasting vibration signal
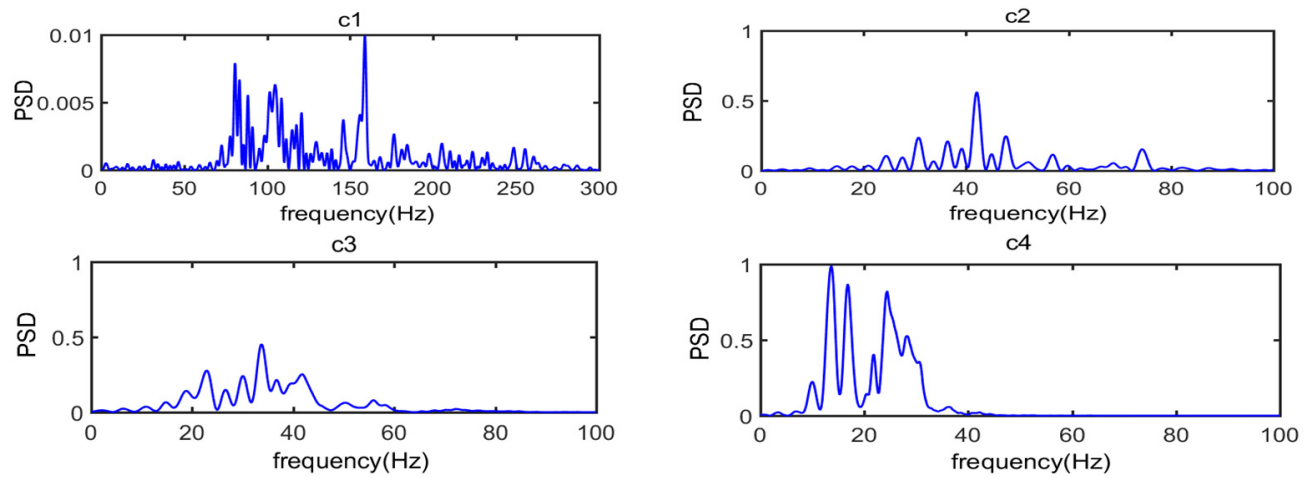

c5
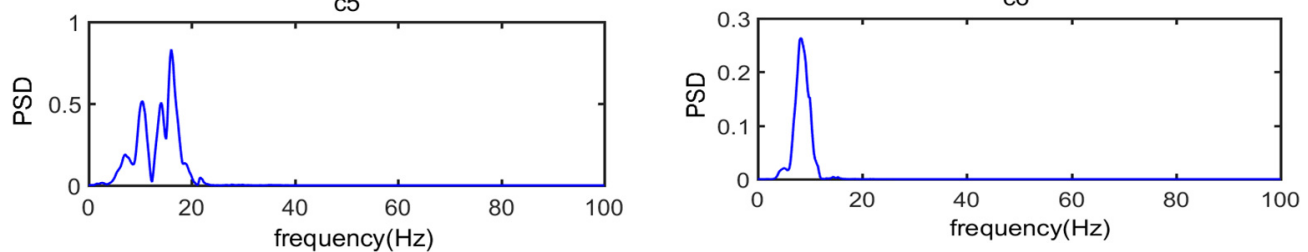

c7
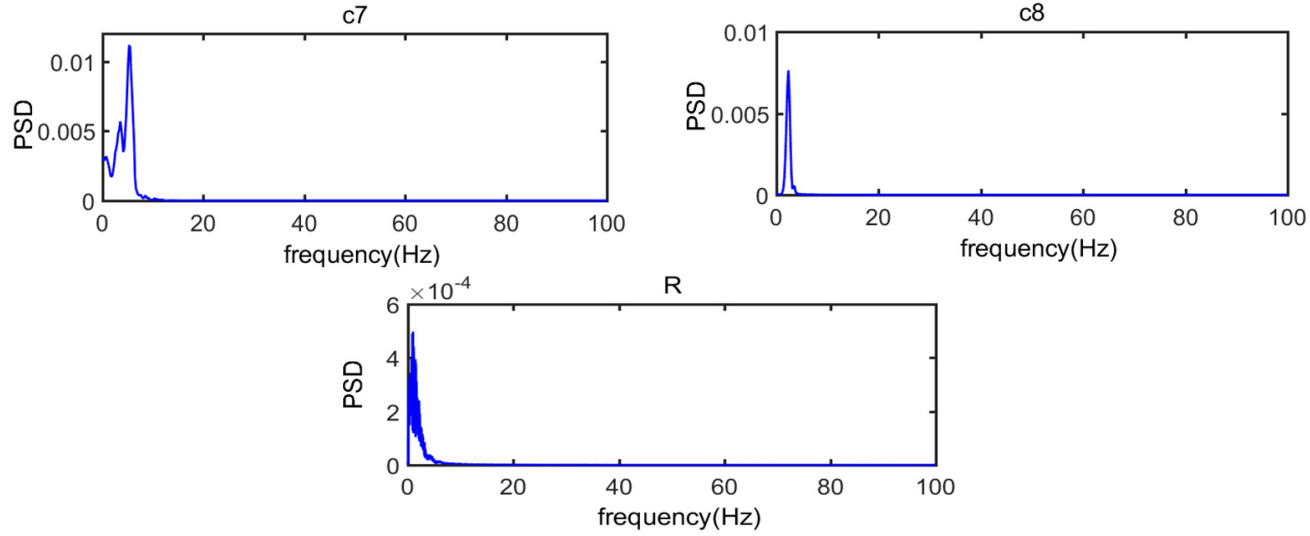

Fig. 9. The power spectral density of IMF component from $\mathrm{c} 1$ to $\mathrm{c} 8$ and $\mathrm{R}$ as surplus

As seen in Fig. 9, the c1 component is usually considered to be high frequency noise signal, it has very small power spectral density value while the range of frequency distribution is wide which mainly vary from $70 \mathrm{~Hz}$ to $270 \mathrm{~Hz}$; In the process of analysis on the original signal, the $\mathrm{c} 1$ component should be removed in order to eliminate the effect of high frequency noise. In terms of the main components of the original vibration signal $c 2, c 3, c 4, c 5$ and $c 6$ component, the dominant frequency distribution range mainly vary from $30 \mathrm{~Hz}$ to $80 \mathrm{~Hz}$, from $10 \mathrm{~Hz}$ to $50 \mathrm{~Hz}$, from $10 \mathrm{~Hz}$ to $40 \mathrm{~Hz}$, from $5 \mathrm{~Hz}$ to $20 \mathrm{~Hz}$ and from $5 \mathrm{~Hz}$ to $12 \mathrm{~Hz}$, respectively; In addition, the 
power spectral density value of $\mathrm{c} 7, \mathrm{c} 8$ and $R$ is very small which corresponding dominant frequency distribution range is below $7 \mathrm{~Hz}$. Thus, it can be seen that the spectrum of intrinsic mode functions signal is abundant which can be divided into multiple sub-seismic frequency bands and most of them are below $80 \mathrm{~Hz}$; This is consistent with the power spectrum density of original vibration signal shown in Fig. 8 where the dominant frequency of the original vibration signal is mainly in the range of $10 \mathrm{~Hz}-80 \mathrm{~Hz}$.

The three-dimensional energy density spectrum of original vibration signal on Hilbert-Huang transform is shown in Fig. 10.

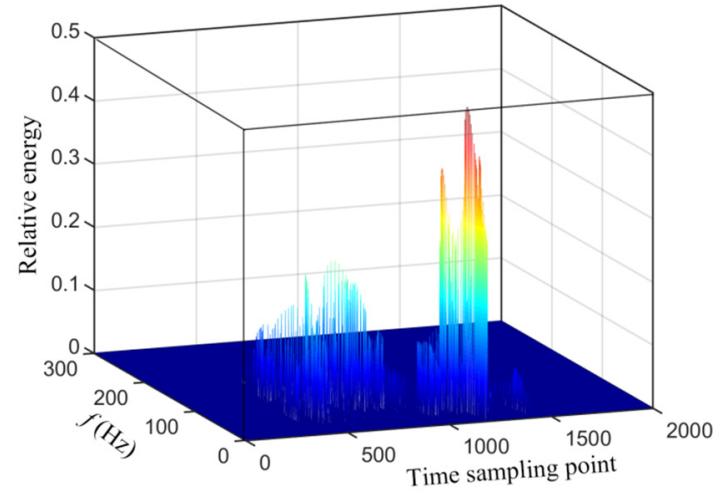

Fig. 10. The three-dimensional energy density spectrum based on Hilbert-Huang transform

Fig. 10 presented the distribution characteristics about energy of blasting vibration signal as the variation of frequency and time; It can be more intuitive to show the distribution of energy on blasting vibration signal with time and frequency, where the color is redder, the energy is greater; We can clearly see that most of the energy distribution in the frequency range is below $100 \mathrm{~Hz}$, in which the energy distribution frequency band higher than $100 \mathrm{~Hz}$ is very small, the energy mainly concentrates on the range of $10 \mathrm{~Hz}-80 \mathrm{~Hz}$ and 360-1250 time sampling point. Dividing time sampling point $360-1250$ by sampling frequency $2000 \mathrm{~Hz}$ is $0.180 \mathrm{~s}-0.625 \mathrm{~s}$, we can obtain the energy mainly concentrates on the scope of $10 \mathrm{~Hz}-80 \mathrm{~Hz}$ and $0.180 \mathrm{~s}-0.625 \mathrm{~s}$. The distribution characteristics about energy density spectrum of original vibration signal based on Hilbert-Huang transform is in accordance with the velocity curve of original vibration signal in Fig. 5 where the time region for velocity vibration amplitude mainly vary from $0.180 \mathrm{~s}$ to $0.625 \mathrm{~s}$ and the power spectral density of original vibration signal in Fig. 8 where the frequency region for power spectral density mainly concentrate on $10 \mathrm{~Hz}-80 \mathrm{~Hz}$.

\subsection{Initiative control for blasting vibration effect}

Blasting vibration effect is affected by the topography, geology and blasting design parameters. To reduce the blasting vibration effect, the corresponding measure should be taken into account with different perspectives, which mainly can be divided into millisecond delay blasting technology, controlling maximum explosive weight per delay and total explosive weight, choosing right powder factor and rational spacing pattern parameter, improving terrain condition by ditch excavation and presplitting blasting technology.

In this paper, the initiative control for blasting vibration effect is mainly by controlling maximum explosive weight per delay and total explosive weight. As seen in the Table 2, in terms of the peak particle velocity of 21 groups monitoring data, the vertical direction is generally greater than horizontal radial and horizontal tangential direction in the near field of blasting source and the peak particle velocity of vertical direction is usually lower than horizontal radial and horizontal tangential direction in the far field of blasting source. Therefore, it is noteworthy that we should take three different direction components of particle vibration velocity rather than single direction 
into account as safety criteria for blasting vibration. "Safety regulations for blasting" (GB6722-2014) points out the allowable particle vibration velocity is subject to the maximum value of three mutually perpendicular components in cartesian coordinate of blasting vibration signal and the vibration frequency is the main vibration frequency of allowable particle vibration velocity. Because the lock gate belongs to new pouring mass concrete with concrete strength grade of $\mathrm{C} 50$ and curing time has been over 28 days at the start of blasting for bedrock excavation on land for open channel project; meanwhile, as for the measured vibration data, the main vibration frequency of the blasting vibration signal is mainly in $10 \mathrm{~Hz}-80 \mathrm{~Hz}$, the initiative control standard of particle vibration velocity is determined to $[\mathrm{V}]=5.0 \mathrm{~cm} / \mathrm{s}$ according to Table 1 of "Safety regulations for blasting" [17] and expert opinion [28].

Table 3. The maximum explosive weight per delay calculated by Eq. (13) to Eq. (15)

\begin{tabular}{|c|c|c|c|c|}
\hline $\begin{array}{c}\text { Blast radial } \\
\text { distance } \\
(\mathrm{m})\end{array}$ & $\begin{array}{c}\text { Horizontal } \\
\text { radial direction }\end{array}$ & $\begin{array}{c}\text { Horizontal } \\
\text { tangential direction }\end{array}$ & $\begin{array}{c}\text { Vertical } \\
\text { direction }\end{array}$ & \multirow{2}{*}{$\begin{array}{c}\text { Maximum explosive } \\
\text { weight per delay }(\mathrm{kg})\end{array}$} \\
\cline { 2 - 4 } & $Q_{x}(\mathrm{~kg})$ & $Q_{y}(\mathrm{~kg})$ & $Q_{z}(\mathrm{~kg})$ & 0.6 \\
\hline 10 & 1.9 & 4.4 & 0.6 & 4.6 \\
\hline 20 & 15.1 & 34.9 & 4.6 & 15.6 \\
\hline 30 & 51.0 & 117.6 & 15.6 & 36.9 \\
\hline 40 & 121.0 & 278.8 & 36.9 & 72.0 \\
\hline 50 & 236.3 & 544.5 & 72.0 & 124.5 \\
\hline 60 & 408.4 & 940.9 & 124.5 & 197.7 \\
\hline 70 & 648.5 & 1494.2 & 197.7 & 295.0 \\
\hline 80 & 968.0 & 2230.4 & 295.0 & 420.1 \\
\hline 90 & 1378.3 & 3175.7 & 420.1 & 576.2 \\
\hline 100 & 1890.7 & 4356.3 & 576.2 & 766.9 \\
\hline 110 & 2516.5 & 5798.2 & 766.9 & 995.7 \\
\hline 120 & 3267.1 & 7527.6 & 995.7 & \\
\hline
\end{tabular}

Due to the phenomenon about field monitoring particle vibration velocity more than initiative control standard of particle vibration velocity is existed, therefore, we should control maximum explosive weight per delay at different distance from the explosion source on the basis of the blast-induced wave propagation law based on Eq. (13), Eq. (14) and Eq. (15). As shown in Table 3 above, the allowable maximum explosive weight per delay is controlled by maximum explosive weight per delay of vertical direction. Supposing the distance between lock gate monitoring point and the explosion source is $50 \mathrm{~m}$, the maximum explosive weight per delay can be evaluated to $72 \mathrm{~kg}$; that is, it can satisfy the lock gate concrete structure safety when the maximum explosive weight per delay dose not greater than $72 \mathrm{~kg}$. In order to guarantee safety of damage control for lock gate and surrounding rock mass under blasting load in Taishan Nuclear Power Station, it is essential that we should strictly control maximum explosive weight per delay and total explosive weight based on above calculation results of Table 3. In the subsequent process of rock blasting, we have achieved excellent effect on blasting control. Summary of experimental blasts details at open channel in Taishan nuclear power station is given in Table 4.

Table 4. Summary of blasts details at open channel in Taishan nuclear power station

\begin{tabular}{|c|c|c|c|c|c|c|c|c|c|}
\hline $\begin{array}{c}\text { No. of } \\
\text { blasts }\end{array}$ & $\begin{array}{c}\text { Diameter } \\
\text { of hole } \\
(\mathrm{mm})\end{array}$ & $\begin{array}{c}\text { Burden } \\
(\mathrm{m})\end{array}$ & $\begin{array}{c}\text { Spacing } \\
(\mathrm{m})\end{array}$ & $\begin{array}{c}\text { Depth } \\
\text { of blast } \\
\text { hole } \\
(\mathrm{m})\end{array}$ & $\begin{array}{c}\text { Length of } \\
\text { stemming } \\
(\mathrm{m})\end{array}$ & $\begin{array}{c}\text { Total } \\
\text { charge } \\
(\mathrm{kg})\end{array}$ & $\begin{array}{c}\text { Maximum } \\
\text { charge per } \\
\text { delay(kg) }\end{array}$ & $\begin{array}{c}\text { Initiation } \\
\text { systems }\end{array}$ & Explosives \\
\hline 56 & 150 & $3-3.5$ & $3-3.5$ & $2-11$ & $1-4$ & $\begin{array}{c}120- \\
2904\end{array}$ & $36-800$ & $\begin{array}{c}\text { Non-electric } \\
\text { shock tube } \\
\text { delay detonator } \\
\text { and milli- } \\
\text { second } \\
\text { connector }\end{array}$ & $\begin{array}{l}\text { Emulsion } \\
\text { explosive }\end{array}$ \\
\hline
\end{tabular}


The measured magnitudes of peak particle velocity and frequency of the 168 blasting vibration data along the horizontal radial, horizontal tangential and vertical direction from 56 blasts were evaluated taking into consideration the established damage criteria of the "Safety regulations for blasting" (GB6722-2014) in China; As required in Table 1, in view of the lock gate belongs to new pouring mass concrete with concrete strength grade of C50 and curing time has been over 28 days at the start of blasting for bedrock excavation for open channel project, the safety criteria of particle vibration velocity for lock gate could be set as $8 \mathrm{~cm} / \mathrm{s}, 10 \mathrm{~cm} / \mathrm{s}$ and $12 \mathrm{~cm} / \mathrm{s}$, respectively when the main vibration frequency is $f \leq 10 \mathrm{~Hz}, 10 \mathrm{~Hz}<f \leq 50 \mathrm{~Hz}$ and $f>50 \mathrm{~Hz}$, respectively. The evaluation of damage risk of the blasts on lock gate according to "Safety regulations for blasting" in China is shown in Fig. 11.

It was observed in Fig. 11 that a major part of the recorded peak particle velocity were below the initiative control standard of particle vibration velocity $[\mathrm{V}]=5.0 \mathrm{~cm} / \mathrm{s}$ and the PPV values versus different frequency for all blasts were below allowable limit of PPV for new pouring mass concrete with curing time over $28 \mathrm{~d}$ described in the safety criteria of "Safety regulations for blasting" in China. This work could be conducive to future design of similar blasting engineering about lock gate damage control.

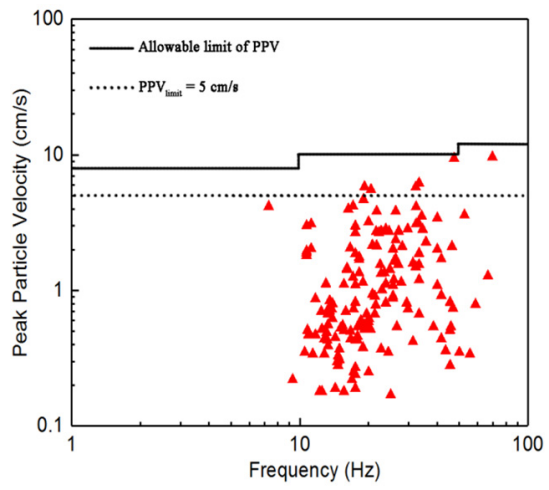

Fig. 11. Evaluation of damage risk of the blasts on lock gate according to "Safety regulations for blasting"

Haibo Li contributed to the conception and design of the study. Xiang Xia and Yaqun Liu contributed significantly to analysis and manuscript preparation; Dr. Zeng performed the data analyses and wrote the manuscript; Hong Zuo and Jinlin Jiang helped perform the analysis with constructive discussions.

\section{Conclusions}

This paper presents the attenuation law and time-frequency characteristics of blasting vibration signal of open channel in Taishan Nuclear Power, At the same time, the initiative control measure for blasting vibration effect is carried out by controlling maximum explosive weight per delay in advance, the main conclusions of the study are drawn as follows:

1) The Sadaovsk empirical formula on regressive analysis along the horizontal radial, horizontal tangential and vertical direction is expressed as $v_{x}=77.3\left(Q^{1 / 3} / R\right)^{1.31}$, $v_{y}=63.2\left(Q^{1 / 3} / R\right)^{1.40}, v_{z}=241.8\left(Q^{1 / 3} / R\right)^{1.56}$, respectively. In terms of the peak particle velocity of monitoring data, the vertical direction is generally greater than horizontal radial and horizontal tangential direction in the near field of blasting source and the peak particle velocity of vertical direction is usually lower than horizontal radial and horizontal tangential direction in the far field of blasting source; therefore, it is noteworthy that we should take three different direction components of particle vibration velocity rather than single direction into account as safety criteria for blasting vibration. 
2) As for those monitoring data, the blasting vibration signal is analyzed by Empirical Mode Decomposition based on Hilbert-Huang transform which is decomposed into 9 intrinsic mode functions from $\mathrm{c} 1$ to $\mathrm{c} 8$ and $\mathrm{R}$ for residual error within the range of $10^{-15}$. The three-dimensional energy density spectrum show the energy mainly concentrates on the scope of $10 \mathrm{~Hz}-80 \mathrm{~Hz}$ and $0.180 \mathrm{~s}-0.625 \mathrm{~s}$ that is in accordance with the velocity curve of original vibration signal where the time region for velocity vibration amplitude mainly vary from $0.180 \mathrm{~s}$ to $0.625 \mathrm{~s}$ and the power spectral density of original vibration signal where the frequency region for power spectral density mainly concentrate on $10 \mathrm{~Hz}-80 \mathrm{~Hz}$, which is much higher than natural frequency of lock gate and is beneficial to structural safety and stability of surrounding rock mass for reducing the probability of resonance.

(3) The initiative control standard of particle vibration velocity is determined to [V] $=5.0 \mathrm{~cm} / \mathrm{s}$ according to "Safety regulations for blasting" and expert opinion, a major part of the recorded peak particle velocity were below the initiative control standard of particle vibration velocity $[\mathrm{V}]=5.0 \mathrm{~cm} / \mathrm{s}$ and the PPV values versus different frequency for all blasts were below allowable limit of PPV for new pouring mass concrete with curing time over $28 \mathrm{~d}$ described in the safety criteria of "Safety regulations for blasting" in China; We have controlled maximum explosive weight per delay at different distance from the explosion source on the basis of the blast-induced wave propagation law in the form of Sadaovsk empirical formula, In the subsequent process of rock blasting, it shown excellent effect on blasting damage control for lock gate and surrounding rock mass.

\section{Acknowledgements}

The authors are very grateful to the editor and unknown referees for suggestions which improved the quality of this paper. In addition, the study is supported by the Key Program of National Natural Science Foundation of China under Grant No. 51439008, National Natural Science Foundation of China under Grant No. 41572307 and National Natural Science Funds for Distinguished Young Scholar of China under Grant No. 41525009.

\section{References}

[1] Zhang X. L., Huang S. T. Blasting Seismic Effect. Seismological Press, Beijing, 1981.

[2] Li Y. Q., Ma S. Z. Explosion Mechanics. Science and Technology Press, Beijing, 1992.

[3] Feng S. Y., Lv Y., Gu Y. C. City Control Blasting. China Rail Press, Beijing, 1996.

[4] Liu D. Z. Practical Manual for Blasting Engineering. Metallurgical Industry Press, Beijing, 2003.

[5] Wei X. L., Zheng B. X. Destructive effect of blasting vibration on nearby structures. Engineering Blasting, Vol. 6, Issue 3, 2000, p. 81-88.

[6] Wang C., Gao C. Blasting vibration monitoring and controlling of underground excavation of light rail station in city. Chinese Journal of Underground Space and Engineering, Vol. 7, Issue 2, 2011, p. $1688-1691$.

[7] Jiang Y. G., Shen Z. W., Yang C. D. Big charge blasting vibration damping and vibration monitoring analysis under intracity complicated environment. Journal of Vibration and Shock, Vol. 31, Issue 1, 2012, p. 156-161.

[8] Lin C. M., Chen L. B., Jiang L. L., et al. Research on blasting stability control technology of largespan highway tunnel with super-small clear spacing at highway expansion project. Chinese Journal of Rock Mechanics and Engineering, Vol. 29, Issue 7, 2010, p. 1371-1378.

[9] Zeng S., Yang S. J., Tan K. X., et al. Experimental research into effect of blasting vibration on stability of surface buildings. Journal of Mining and Safety Engineering, Vol. 25, Issue 2, 2008, p. 176-179.

[10] Wang H. B., Zong Q. Study of blasting vibration character of soft rock roadway excavation in coalmine. Chinese Journal of Rock Mechanics and Engineering, Vol. 31, Issue 2, 2012, p. 3876-3881.

[11] Zong Q., Wang H. B., Xu Y., et al. Analysis of blasting seismic wave signal in coalmine roadway excavation based on HHT method. Journal of Vibration and Shock, Vol. 32, Issue 15, 2013, p. 116-120. 
[12] Huo Y. J. Blasting vibration effects on structures and safety analysis. Blasting, Vol. 20, Issue 1, 2003, p. $1-6$.

[13] Xu X. S. Blasting safety technologies in the circumstance of cross tunnels with small interval. Industrial Safety and Environmental Protection, Vol. 36, Issue 12, 2010, p. 36-37.

[14] Jiang D. Y., Chen Y., et al. Blasting vibration monitoring and control technology of super small clear distance cross tunnel. West-China Exploration Engineering, Vol. 20, Issue 10, 2008, p. 188-191.

[15] Zong Q., Wang H. B., Zhou S. B. Research on monitoring and controlling techniques considering effects of seismic shock. Chinese Journal of Rock Mechanics and Engineering, Vol. 27, Issue 5, 2008, p. 938-945.

[16] Lu W. B., Li H. B., Chen M., et al. Safety criteria of blasting vibration in hydropower engineering and several key problems in their application. Chinese Journal of Rock Mechanics and Engineering, Vol. 28, Issue 8, 2009, p. 1513-1520.

[17] GB6722-2014. Safety Regulations for Blasting. The National Standards Compilation Group of People's Republic of China. Standards Press of China, Beijing, China, 2014.

[18] Semion K., Thomas Flatley P., et al. On the Hilbert-Huang Transform Data Processing System Development. National Aeronautics and Space Administration Goddard Space Flight Center, Darrell Smith Orbital Sciences Corporation, 2001.

[19] Huang N. E., Shen Z., Long S. R., et al. The empirical mode decomposition and the Hilbert spectrum for nonlinear and non-stationary time series analysis. Proceedings of the Royal Society of London, Vol. 5, Issue 4, 1998, p. 903-995.

[20] Yan Z. X., Wang Y. H., Jiang P., et al. Study on measurement of blast-induced seism and building safety criteria. Chinese Journal of Rock Mechanics and Engineering, Vol. 22, Issue 11, 2003, p. 1907-1911.

[21] Wang X. G., Yu Y. L. On several problems of safety criterion of blasting vibration. Engineering Blasting, Vol. 7, Issue 2, 2001, p. 88-92.

[22] Langefors U., Kihlstrom B., Westerberg H. Ground vibration in blasting. Water Power, 1958, p. $335-421$.

[23] Edwards A. T., Northwood T. D. Experimental studies of the effects of blasting on structures. Engineer, Vol. 210, 1960, p. 538-546.

[24] Duvalland W. I., Fogelson D. E. Review of Criteria for Estimating Damage to Residences from Blasting Vibration. US Bureau of Mines Report Investigation, Washington, 1962, p. 59-68.

[25] Northwood T. D. Blasting vibrations and building damage. Engineer, Vol. 215, 1963, p. 973-978.

[26] Bolinger G A. Blasting Vibration Analysis. Science and Technology Press, Beijing, 1975.

[27] Li X. B., Ling T. H., Zhang Y. P. Analysis of Blast Vibration Signals Theories and Methods. Science Press, Beijing, 2009.

[28] Lin J. H. Blast vibration safety and controlling in water intake area of the second phase of Jiulong River north-diversion project. China Rural Water and Hydropower, Vol. 53, Issue 2, 2011, p. 91-93.

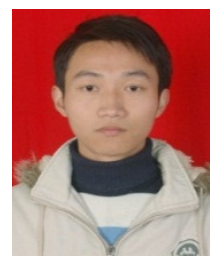

Yongqing Zeng was born in February 1991 and received his M.S. degree from Anhui University of Science and Technology, Huainan, China, in 2016. In the same year, Zeng started his Ph.D. program in University of Chinese Academy of Sciences, Beijing, China and State Key Laboratory of Geomechanics and Geotechnical Engineering, Institute of Rock and Soil Mechanics, Chinese Academy of Sciences, Wuhan, China. Yongqing Zeng's Ph.D. program focuses on rock dynamic mechanics, for example analysis on timefrequency characteristics and delay time identification for blasting vibration signal and research on damage control of rock mass under blasting load. Yongqing Zeng has authored or co-authored 6 journal papers and 5 international conference papers to date.

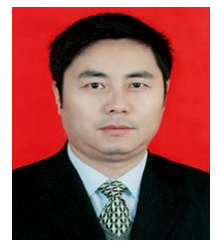

Haibo Li received the Ph.D. degree from Institute of Rock and Soil Mechanics, Chinese Academy of Sciences, Wuhan, China, in 1999. Li is the distinguished Professor of State Key Laboratory of Geomechanics and Geotechnical Engineering, Institute of Rock and Soil Mechanics, Chinese Academy of Sciences, Wuhan, China. His research interests cover rock dynamics and earthquake engineering. He is the author of 2 books and has published more than 90 technical papers. 


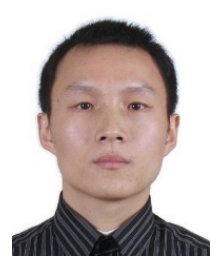

Xiang Xia received the Ph.D. degree from Institute of Rock and Soil Mechanics, Chinese Academy of Sciences, Wuhan, China, in 2006. He is now an Associate Professor in Institute of Rock and Soil Mechanics, China. His research interests are mainly on rock dynamic, the safety evaluation of geotechnical engineering subjected to dynamic loads. He is an author of more than 25 scientific papers with over 10 indexed in major scientific databases.

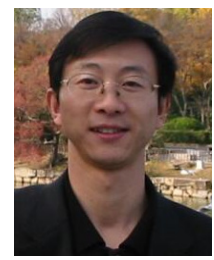

Yaqun Liu received the Ph.D. degree from Institute of Rock and Soil Mechanics, Chinese Academy of Sciences, Wuhan, China, in 2009. He is now a Professor in Institute of Rock and Soil Mechanics, China. His research interests are mainly on rock dynamic, seismic stability analysis of layered rock slope and in situ stress measurements. he is an author of more than 30 research papers. with over 18 indexed in major scientific databases.

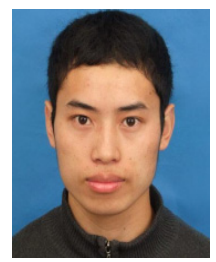

Hong Zuo was born in February 1993 and received his Bachelor's Degree from the Huazhong University of Technology and Sciences, Wuhan, China, in 2016. In the same year, Zuo started his Master program in University of Chinese Academy of Sciences, Beijing, China and State Key Laboratory of Geomechanics and Geotechnical Engineering, Institute of Rock and Soil Mechanics, Chinese Academy of Sciences, Wuhan, China. Hong Zuo's Master program focuses on the multiphase flow and the coupling LBM and DEM; Hong Zuo has authored or co-authored 1 journal papers and 2 international conference papers to date.

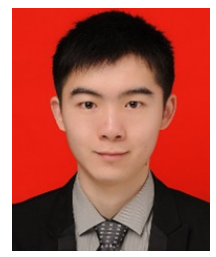

Jinlin Jiang was born in October 1993 and received his Bachelor's Degree from Wuhan University, Wuhan, China, in 2016. In the same year, Jiang started his Master program in University of Chinese Academy of Sciences, Beijing, China and State Key Laboratory of Geomechanics and Geotechnical Engineering, Institute of Rock and Soil Mechanics, Chinese Academy of Sciences, Wuhan, China. Jinlin Jiang's Master program focuses on rock dynamic mechanics, for example acoustic emission characteristics and failure mechanism of fractured rock under intermediate strain rate. Jinlin Jiang has authored or co-authored 2 journal papers and 1 international conference papers to date. 